\title{
PREPAID METER TARIFFING FOR ACTUAL POWER CONSUMPTION IN AN AVERAGE HOUSE HOLD: A CASE STUDY OF NIGERIA DISCOs
}

\author{
U. C. Ogbuefi ${ }^{1, *}$, P. C. Ene ${ }^{2}$ and P. A. Okoro ${ }^{3}$ \\ 1,3, DePARTMENT OF EleCtriCAL ENGINEERING, UNIVERSITY OF NigeRIA, NSUKKA, ENUGU STATE, NIGERIA \\ 2, DEPARTMENT OF ELECTRICAL AND ELECTRONICS ENGINEERING, ENUGU STATE UNIVERSITY OF SCIENCE AND \\ TECHNOLOGY, ENUGU STATE, NIGERIA \\ E-mail addresses: ${ }^{1}$ ucchsamo@gmail.com, ${ }^{2}$ eneh.princewill@esut.edu.ng, \\ 3 anthony.okoro.pg01001@unn.edu.ng
}

\begin{abstract}
Prepaid meters have many applications in generation, transmission and distribution of electric power in Nigeria, this makes their actual power measurement to be an important issue. In this work, actual power consumption of each load was determined and was used to study the time each load will use to consume 30.8 EEDC units when it is constantly connected to power supply. The analytical method was used to investigate the collected date for different appliance consumption rate with respect to time. This experiment was conducted in Achara Layout of Enugu South Local Government Area, Enugu state. Each of the load was subjected to test to determine the current and voltages across them. The actual power consumption of each load was calculated. The time for each actual power to completely consume $\mathbf{3 0 . 8}$ units was calculated. The corresponding amount in naira per day of the actual consumption of each load was calculated. The results show that, phone and lighting points will take longer time (18421.05 and 5589.8 hours) to drain the 30.8 units; while electrical pressing iron will take 8.95 hours to drain the 30.8 units. It is also seen that lighting points and phones have the least and highest consumption cost per day. By optimal combination of these loads, it will make economic sense for the subscribers of prepaid meter, and hence reduce the phobia faced by the subscribers (if not total elimination).
\end{abstract}

Keywords: Actual Power, Economic Sense, Prepaid meter, Nigeria DISCOs, Tariff.

\section{INTRODUCTION}

Energy billing in Nigeria till date, is based on cost reflective tariff which the end-users can hardly understand or analyze [1]. This has resulted in riots and criticisms of the utilities. Some communities in Ajeromi/Ifelodun of Lagos State resorted to self-help and threat of agitations on Enugu Electricity Distribution Company (EEDC) officials in 2016 in charge of their location. This is as a result of high cost of billing to the residents of that location [2].

Besides, the current approach of estimating and dispatching energy bills for unmetered residents is grossly ineffective and hostile. This discourages the users from making efforts to pay their bills on time. These issues necessitated the installation of prepaid metering systems in Nigeria DISCOs. The applications of prepaid meter for billing have remained vital in
DISCOs industrial processes notwithstanding some challenges faced by subscribers and the utilities. Prepaid meters have many functions in the consumers' apartment such as: load indication, load evaluation, and load isolation due to its precise, wide, simple and continuous control characteristics. Prepaid meter integrated with SMS function sends subscriber's energy alert of their prepaid meter. Some subscribers do not have time to monitor their prepaid meter, when there is an SMS alert from their prepaid meter that their unit will soon exhaust, they will react to the SMS [3]. The benefits of the prepaid meter techniques to both the utilities and customers are;

i. For the utilities, installation of the metering system, improves cash flow/revenue, billing systems/account posting is eradicated, bad debts are avoided, disconnection/reconnection fees are

\footnotetext{
* Corresponding author, tel: $+234-803-584-3797$
} 
Prepaid Meter Tariffing for Actual Power Consumption in an Average House Hold: A CaSe Study of... , U. C. Ogbuefi, et. al

eliminated, and estimated/inaccurate billing are avoided. Also, undue access into consumer's premises is eliminated. This will improve overall performance of the utility company

ii. For the customers, it facilitates budget management, controls energy usage, and eliminates physical disconnection and reconnection fee among others [1].

The second case will make the consumers to use their energy optimally and control electricity theft. But these advantages to the customers do not fully satisfy their interest. They still have phobia that their electric unit will vanish when loads are connected. This phobia is as a result of absent of information on actual power consumption in average household. Thus the aim of this research. The absence of actual power consumption information in average household apartment has often made many prepaid meter subscribers in Nigeria to be at disagreement with electricity distribution companies. In rural and urban areas in Nigeria, almost all activities are associated with electricity. It can be seen from the human life that their activities are always dependent on electricity. This makes the actual power consumption information a very important issue [4].

With the increase in acceptance of prepaid metering systems in Nigeria, metering and billing become a big concern to customers and energy utilities. Till date, electricity generation, transmission, and distribution in a regulated market are still having various metering and billing challenges.

Lack of actual power consumption awareness and huge bills for unmetered customers are the major fears associated with the existing metering models. There are various costs associated with different customers. These costs vary with public consumers, individual household connections, and institutional customers [5]. Prepaid meters are generally used in electricity billing for ease and optimal load management, but the reaction of most subscribers towards its use is not encouraging. Most subscribers have serious fear and psychological challenges in using prepaid meter. Like

i. Most customers are not psychologically calm while using prepaid meter;

ii. They fear that their units will evaporate when loads are connected to the supply, hence are not comfortable using their appliances.

iii. It leads to behavioural change on the customers' side like energy conservation.

iv. Using of alternative energy sources
Customers using prepaid meter billing method should not be allowed to suffer from these challenges as remedy exist. There are two remedies to these challenges, they include:

1. Sensitization on Optimal Load Management: Sensitizations has been ongoing by DISCOs in Nigeria with respect to load management and optimization but most customers are not satisfied with their teachings.

2. Analysis of Actual Power Consumption by each Electrical Appliances: This is what this research tends to address. Here, the actual power consumption of each of the appliances in an average house were determined to create awareness to the prepaid meters subscribers.

This actual power consumption analysis has a lot of benefits, and the beneficiaries include but not limited to: Distribution Company of Nigeria. When the customers understand that the power consumption of most electrical loads are below their rated power, demand for prepaid meters will increase.

The customers will be at ease using the meter, and their paranoia will be eliminated. It will also reveal to the customers how to combine their loads to make economic sense, reduce fear and eliminate their negative belief of prepaid meter.

\section{BACKGROUND OF THE RESEARCH REVIEW}

Some previous works and contributions have been done on prepaid meter. Most of these works are on how to control electricity theft by the use of prepaid metering system and importance of prepaid meters. None has done analysis on actual power consumption of average household in order to reduce the phobia and psychological effects customers face while using prepaid meter. Prepaid meters is one of the promising ways to increase performance of the utilities and help consumers to optimally manage their power [1]. They highlighted the advantages of prepaid meter on the side of utilities and customers. However, they did not look at the psychological effects like fear and bogus believe of vanishing of units as believed by customers. G. H. Yang et al [7] demonstrated using basic economic theory that there are four possible channels through which a reduction in electricity consumption can be achieved by the adoption of a prepaid meter. These include: nudging, price effects, information provision, and costs of being disconnected. The study adopts a matching approach and a difference-indifferences method to estimate empirically the impact of a prepaid electricity plan on residential electricity 
consumption. The results show that the prepaid program is associated with a $12 \%$ reduction in electricity usage [7].

$\mathrm{N}$. Mohammad et al presents some measures to control meter bypassing and tampering by the use of bidirectional GSM communication. The system uses SMS to communicate the vendors when the line is by passed [8]. But the issue of psychological effects to subscribers while using prepaid metre was not addressed.

S. Karnouskos, used data from Cape Town, South Africa to examine the effects of prepaid electricity metering on residential consumption and electric utility revenue and costs. From their analysis, electricity usage decreases by about 13 percent as a result of the change in meter type [9]. This case study satisfies the important of prepaid meter to utilities as produced by [1] but the fall of power usage was as a result of fear and psychological effects most prepaid meter subscribers faced.

\subsection{Gap in Literature}

$[1,6,7$ and 9$]$ produced the importance of prepaid meter to the utilities and customers whereas [8] produces a way to control electricity theft by prepaid meter subscribers. None of these authors did a work on analysis of actual power consumption in average household. With the actual power consumption knowledge, the consumers will be at ease while using prepaid meter. Bogus believe of unit vanishing when load are connected to them will be eliminated.

\section{METHODOLOGY AND MATERIAL}

The analytical method was used to investigate the collected date for different appliance consumption rate with respect to time. For the experiment, 30.8 EEDC units were used. During the event of the experiment, a voltmeter and an ammeter was connected to each load as shown in Figures $1 \mathrm{~A}$ to $1 \mathrm{M}$. Readings of each load was taken to determine the actual consumption, and time for each load to consume 30.8 EEDC units and amount in Naira each load consume per day. Table 1 shows the loads subjected to test during the experiment as also shown in Figure 1.

3.1 The actual power, time of consumption and cost of electricity analysis of the loads

The actual power consumption of each load was calculated using Equation 1.

$$
P=I \times V \times \cos \theta
$$

Where: $\mathrm{P}$ is the actual power consumption in watts, $I$ is the measured current of each load during the experiment in amperes. $\mathrm{V}$ is the measured voltage drop across each load during the experiment in volts. The time it will take each load to consume 30.8 EEDC units was calculated using Equation 2.

$$
t=\frac{E \times 1000}{P}
$$

Where: $\mathrm{E}$ is Energy in Kilo watt hour. $\mathrm{P}$ is the actual power consumption of each load in watts. ' $t$ ' is the numbers of hours it will take each load to consume 30.8 EEDC units when they are continuously connected to power supply

The cost of electricity of each load per day was calculated using Equation 3.

$$
\text { Cost of Electricity }=\frac{P \times t}{1000 \times \text { Price per Kwh }}
$$

The 30.8 EEDC units cost 1000 Naira. Therefore, price per unit is 32 Naira per Kwh. This cost corresponds to R2S customers (Customers with consumption above 50 kilowatt). In this analysis, we assumed that loads were connected constantly for a day (24hours).

Table 1: Loads subjected to test during the experiment

\begin{tabular}{llll}
\multicolumn{3}{c}{ experiment } \\
\hline S/N & Loads Type & $\begin{array}{l}\text { Power } \\
\text { (W) }\end{array}$ \\
\hline 1 & Lighting points & (Energy & 15 \\
& saving) & \\
2 & Electric Fan & 130 \\
3 & TV set & 95 \\
4 & DVD home theatre & 95 \\
5 & Go TV cable decoder & 30 \\
6 & 2hp AC & 1800 \\
7 & 1hp AC & 746 \\
8 & Micro wave & 700 \\
9 & Iron & 2200 \\
10 & Laptop & 65 \\
11 & Refrigerator & $95 \mathrm{~W} / 0.5 \mathrm{Kwh}$ \\
12 & Deep freezer & $115 / 1.2 \mathrm{Kwh}$ \\
13 & Washing machine & 1000 \\
14 & Phone & 1 \\
15 & Electric kettle & $2520-3000$ \\
16 & Electric boiler & 500 \\
15 & Miscellaneous & 100 \\
\hline
\end{tabular}




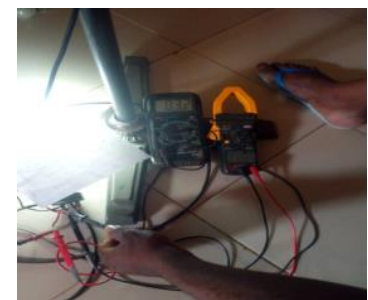

A: Electric fan voltage and current measurement

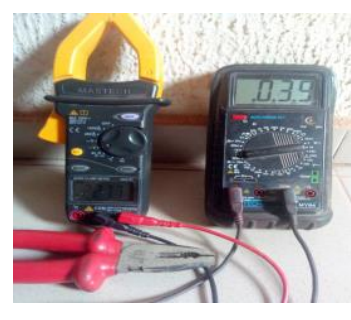

E: TV set voltage and current Measurement

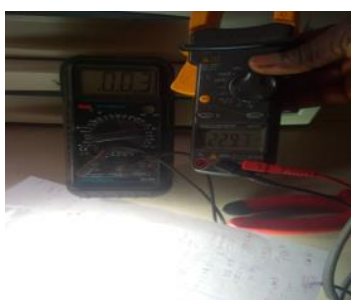

B: Lighting point voltage and current measurement

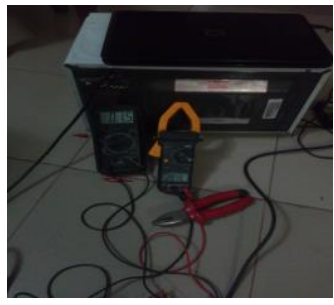

F: Laptop voltage and current Measurement

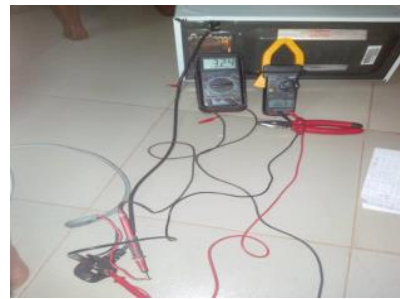

C: Microwave voltage and current Measurement

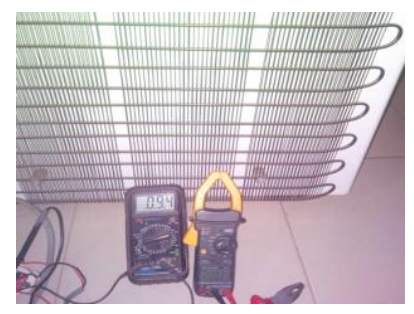

G: Refrigerator voltage and current measurement

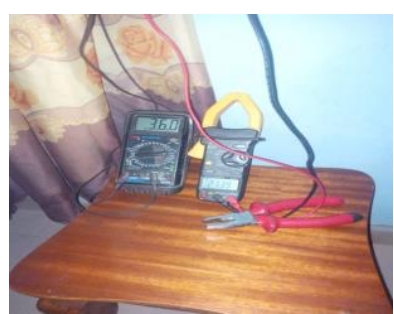

D: $1 \mathrm{Hp} \mathrm{AC}$ voltage and current measurement

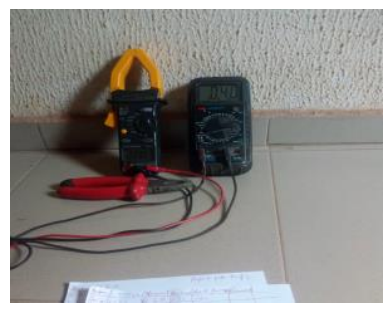

H: Go TV cable voltage and current decoder measurement

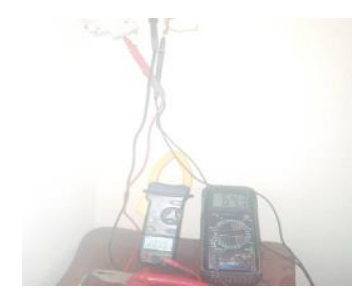

I: $2 \mathrm{Hp}$ AC voltage and current Measurement

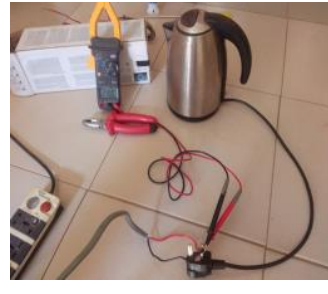

$\mathbf{J}$ : Electric kettle voltage measurement.

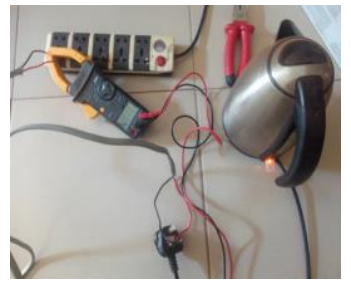

K: Electric kettle current measurement

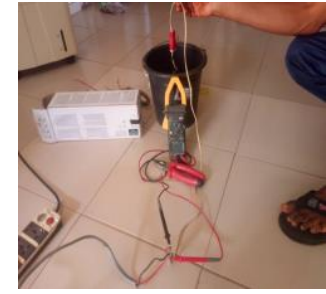

L: Electric boiler voltage measurement.

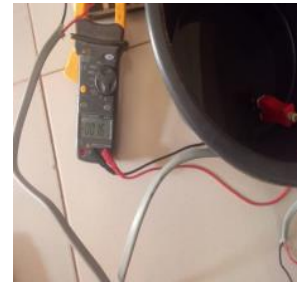

M: Electric boiler current measurement.

\section{Fig. 1: Loads Subjected to Test during the Experiment}

\section{RESULTS}

Table 2 shows the load type, numbers of points of the load, unit power rating of each load, unit actual consumption of each load and the total actual power consumption of the loads. Table 3 shows the load type, number of points, unit actual power consumption of the load, the unit time for the load to consume 30.8 units of EEDC power, and total time it will take the number of points to consume the unit.

Table 4: Shows the load type, number of points, unit actual power consumption of the load, unit per day consumption cost in naira and the total per day cost. Figure 2 to 4 represent the plot of the results in bar chart. Figure 3 shows the plot of unit actual power consumption (watts) and unit time (hours) of consumption. Figure 4 shows the plot of unit actual power consumption (watts) and unit per day consumption cost (Naira).

\subsection{Discussion of Results}

In Table 4.1, we can see that the actual power consumption of electric kettle, boiler, washing machine, air conditioners, lighting point (energy saving bulb), fan, TV set and electric fan are much lesser than their rated power. The actual power consumption of DVD home theatre, GO TV decoder, Electric pressing iron, refrigerator and laptop are higher than their rated power. This is also evident in Figure 1.

Table 2: Experimental result of actual power consumption of the appliances of three-bedroom

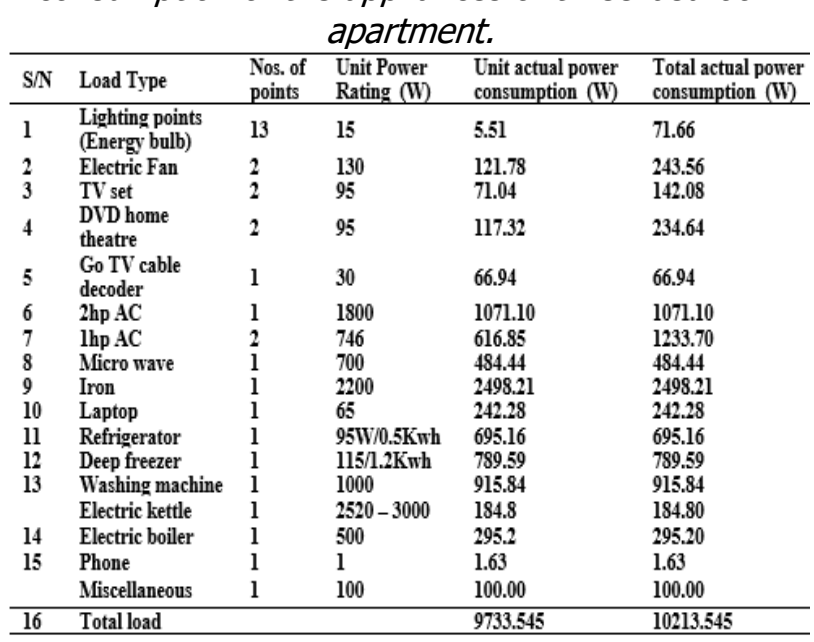


Prepaid Meter Tariffing for Actual Power Consumption in an Average House Hold: A Case Study of... , U. C. Ogbuefi, et. al

Table 3: Calculated time for each appliance to consume 30.8 units of EEDC power.

\begin{tabular}{|c|c|c|c|c|c|}
\hline $\mathrm{S} / \mathrm{N}$ & Loads Type & $\begin{array}{l}\text { Nos. of } \\
\text { points }\end{array}$ & $\begin{array}{l}\text { Unit actual power } \\
\text { consumption (W) }\end{array}$ & $\begin{array}{l}\text { Unit Time } \\
\text { (hours/days) }\end{array}$ & $\begin{array}{l}\text { Total time in } \\
\text { hours (Days) }\end{array}$ \\
\hline 1 & $\begin{array}{l}\text { Lighting points } \\
\text { (Energy bulb) }\end{array}$ & 13 & 5.51 & $\mathbf{5 5 8 9 . 8 0}(\mathbf{2 3 3})$ & 429.99 (18) \\
\hline 2 & Electric Fan & 2 & 121.78 & $252.92(11)$ & $126.46(5.5)$ \\
\hline 3 & TV set & 2 & 71.04 & 433.56 (18) & $216.78(9)$ \\
\hline 4 & DVD home theatre & 2 & 117.32 & 262.53 (11) & $131.27(5.5)$ \\
\hline 5 & $\begin{array}{l}\text { Go TV cable } \\
\text { decoder }\end{array}$ & 1 & 66.94 & 460.11 (19) & $460.11(19)$ \\
\hline 6 & $2 \mathrm{hp} \mathrm{AC}$ & 1 & 1071.10 & $28.76(1.2)$ & $28.76(1.2)$ \\
\hline 7 & $\operatorname{lhp} A C$ & 2 & 616.85 & $49.93(2)$ & 24.97 (1) \\
\hline 8 & Micro wave & 1 & 484.44 & $63.58(2.6)$ & $63.58(2.6)$ \\
\hline 9 & Iron & l & 2498.21 & $8.95(0.4)$ & $8.95(0.4)$ \\
\hline 10 & Laptop & 1 & 242.28 & $127.13(5.3)$ & $127.13(5.3)$ \\
\hline 11 & Refrigerator & 1 & 695.16 & $44.31(1.8)$ & $44.31(1.8)$ \\
\hline 12 & Deep freezer & 1 & 789.59 & $39.00(1.6)$ & 39.00 (1.6) \\
\hline 13 & Washing machine & 1 & 915.84 & $33.63(1.4)$ & $33.63(1.4)$ \\
\hline 14 & Electric kettle & 1 & 184.8 & $166.67(7)$ & $166.67(7)$ \\
\hline 15 & Electric boiler & 1 & 295.2 & $104.33(4.3)$ & $104.33(4.3)$ \\
\hline 16 & Miscellaneous & 1 & 100.00 & $308.00(13)$ & $308.00(13)$ \\
\hline 17 & Phone & 1 & 1.63 & $\begin{array}{l}18895.71 \\
(787)\end{array}$ & $18421.05(768)$ \\
\hline \multicolumn{3}{|c|}{ Total load } & 9733.545 & $3.16(0.13)$ & $3.0156(0.12)$ \\
\hline
\end{tabular}

Table 4: Calculated cost for each appliance when operated constantly in a day

\begin{tabular}{|c|c|c|c|c|c|}
\hline $\mathrm{S} / \mathrm{N}$ & Loads Type & $\begin{array}{l}\text { Nos. of } \\
\text { points }\end{array}$ & $\begin{array}{l}\text { Unit actual power } \\
\text { consumption (W) }\end{array}$ & $\begin{array}{l}\text { Unit per day } \\
\text { consumption } \\
\text { cost (A) [Eq. 3] }\end{array}$ & $\begin{array}{l}\text { Total per } \\
\text { day cost }(\mathrm{A})\end{array}$ \\
\hline 1 & $\begin{array}{l}\text { Lighting points } \\
\text { (Energy bulb) }\end{array}$ & 13 & 5.51 & 0.004 & 0.054 \\
\hline $\begin{array}{l}2 \\
3\end{array}$ & $\begin{array}{l}\text { Electric Fan } \\
\text { TV set }\end{array}$ & $\begin{array}{l}2 \\
2\end{array}$ & $\begin{array}{l}121.78 \\
71.04\end{array}$ & $\begin{array}{l}0.091 \\
0.053\end{array}$ & $\begin{array}{l}0.182 \\
0.106\end{array}$ \\
\hline 4 & $\begin{array}{l}\text { DVD home } \\
\text { theatre }\end{array}$ & 2 & 117.32 & 0.088 & 0.176 \\
\hline 5 & $\begin{array}{l}\text { Go TV cable } \\
\text { decoder }\end{array}$ & 1 & 66.94 & 0.050 & 0.050 \\
\hline 6 & $2 \mathrm{hp} \mathrm{AC}$ & 1 & 1071.10 & 0.803 & 0.803 \\
\hline 7 & $\operatorname{lnp} A C$ & 2 & 616.85 & 0.453 & 0.925 \\
\hline 8 & Micro wave & 1 & 484.44 & 0.363 & 0.363 \\
\hline 9 & Iron & 1 & 2498.21 & 1.874 & 1.874 \\
\hline 10 & Laptop & 1 & 242.28 & 0.182 & 0.182 \\
\hline 11 & Refrigerator & 1 & 695.16 & 0.033 & 0.033 \\
\hline 12 & Deep freezer & 1 & 789.59 & 0.592 & 0.592 \\
\hline \multirow[t]{3}{*}{13} & Washing machine & 1 & 915.84 & 0.521 & 0.521 \\
\hline & Electric kettle & 1 & 184.8 & 0.139 & 0.139 \\
\hline & Electric boiler & 1 & 295.2 & 0.221 & 0.221 \\
\hline 14 & Miscellaneous & 1 & 100.00 & 0.231 & 0.231 \\
\hline
\end{tabular}

Legend: L.P: Lighting points (Energy saving bulb), E.F: Electric Fan, T.V:TV set, D.H.T:DVD home theatre, G.T.C.D: Go TV cable decoder, T.L: Total Load, M.W: Micro wave, Ref.: Refrigerator, D.F: Deep freezer, E.K: Electric kettle, E.B: Electric boiler, W.M: Washing machine, Miscel.: Miscellaneous, U.P.R: Unit Power Rating, U.A.P.C: Unit Actual Power Consumption, U.T: Unit time, U.P.D.C: Unit per day cost

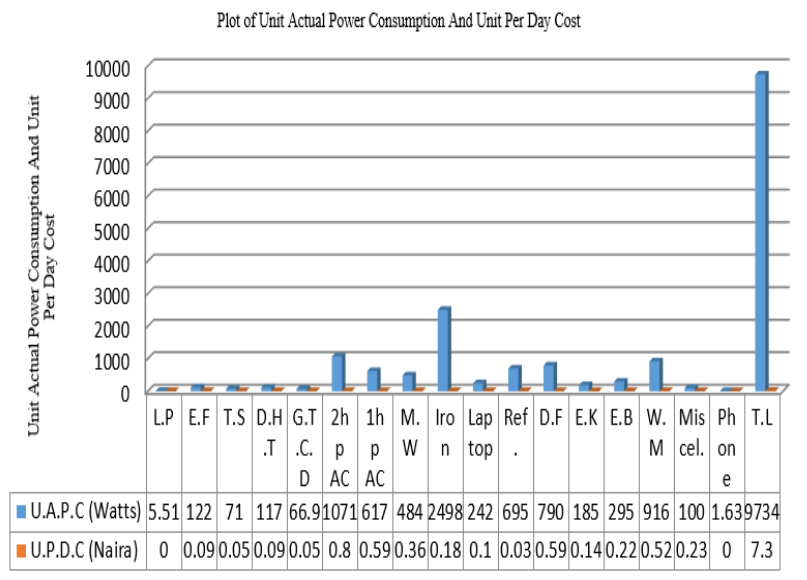

Figure 4: Plot of Unit actual power consumption (Watts) and Unit per day cost (naira)

The reason for the high actual power consumption of refrigerator is that at start, it draws much current to chill the items put in it. Once the refrigerator is chill, it will regulate itself and start consuming power that is lower than its rated value. From this, we can see that the actual consumption of some electrical appliances is not their rated power.

From Table 3 and Figure 2, we could see that lighting point and phones will take longer time of 5589.8 and 18895.7hours respectively to drain 30.8 units of EEDC power. From Table 4, consumption cost analysis, reveals that phones and lighting point have lowest consumption cost of $\mathrm{A} 0.0012$ and $\mathrm{N} 0.004$ per day.

\section{CONCLUSION}

The experimental and analysis of the actual power consumption of each of the load was conducted and the results gotten were used to determine the time it will take each of the load to drain 30.8 EEDC units. The price in Naira for actual consumption of each load was also determined. The results gotten shows that phone and lighting points will take longer time to consume the unit, while electrical pressing iron will take 8.95hours to consume same units. The price in Naira per lighting point and phone consumption in a day is $\mathrm{N} 0.0012$ and $\mathrm{A} 0.004$ respectively; while that of pressing iron is $\mathrm{A1}$ 1.874. By optimal combination of these loads, the subscribers will economize their units to their best maximum benefit. The information from this research work will help to minimize or totally eradicate the paranoia which the electricity consumers have against prepaid meter usage.

\subsection{Recommendation}

Our recommendations include but not limited to:

1) Nigeria DISCOs should be giving bonus to customers that are using electricity in the night. This will encourage the customers to be using most of their appliances in the night, thereby reducing peak demand during the day for commercial consumers. This will increase reliability of power.

2) Nigeria DISCOs should let the public know that most of the appliance like: lighting point (energy bulb) fan, TV set, Electric kettle, electric boiler, 
Prepaid Meter Tariffing for Actual Power Consumption in an Average House Hold: A CaSe Study of... , U. C. Ogbuefi, et. al

micro wave, washing machine, etc., does not consume power up to their rated values. This will help the consumers to be at ease while using utility supply.

\section{REFERENCES}

[1] Prepaid electricity meters and issues related to implementation of Prepaid metering systems. Availableonline:http://www.energycentral.net/ar ticle/05/07/prepaid-electricity-metersandIssues-related-implementation-prepaidmetering-systems. Date Accessed: 02/15/2017.

[2] "Protest on high electricity bill". Available: http://authorityngr.com/2016/11/AjeromiIfelodun-residents-beat-EEDC-officials-protesthigh-electricity-bill. Date Accessed: 01/17/2017.

[3] E. A. Ogujor and P. O. Otasowie, "The impact of the pre-paid meter on revenue generation in Nigeria", The Pacific Journal of Science and Technology, 11:1 (2010) $138-142$.

[4] Z. Hussain, S. Memon, S. Zardari, R. Shah, and Z. 28 , no. 4, pp. 113-120, 2016.
[5] K. C. Okafor, R. M. Onoshakpor, Okoro Nkem Jenifer, Adaora Angela Obayi, "Enterprise Energy Analytic Cloud Portal for User-Centric On Demand Profile Access in Smart Green Energy Management System", IEEE 2017, pp 247 - 256, 2017.

[6] A guide to smart metering, an independent report from Special Report Publishing distributed in The Daily Telegraph UK, 4th Dec., pp. 1 -16, 2008.

[7] G. H. Yang and V. O. K. Li. Energy management system and pervasive service-oriented networks. Proceedings of 1st IEEE International Conference on Smart Grid Communications, 2010, pp.1-6.

[8] N. Mohammad, A. Barua, M. Abdullah Arafat, "A Smart Prepaid Energy Metering System to Control Electricity Theft", IEEE International Conference on Power, Energy and Control, pp 562 - 565, 2013.

[9] S. Karnouskos. "Crowd sourcing information via mobile devices as a migration enabler towards the Smart Grid". Proceedings of $11^{\text {th }}$ IEEE International Conference on Smart Grid Communications (Smart Grid Comm), pp.67-72, 2011. 